\title{
¿UEREMOS, DE VERDAD, RESOLVER NUESTRO GRAVE PROBLEMA DEL PARO?
}

\author{
Por Fernando BIANCHI
}

Todos los partidos políticos y sindicatos han declarado repetidamente que el principal problema que tenemos hoy en España es el problema del paro, y que para su solución no se regateará ningún esfuerzo.

Que el problema actual del paro es angustioso en España nadie lo niega, y no solamente por el alto porcentaje de paro existente entre nuestros trabajadores, sino además porque más de la mitad de los parados no perciben ningún tipo de ayuda económica. Sin contar con que las perspectivas según la OCDE, es que la tasa de paro seguirá subiendo y superará el 17 por 100 en 1983.

Ante esta grave situación, ¿d de verdad, todos, queremos resolver el problema del paro? Porque su solución precisa del esfuerzo y sacrificio de todos los españoles, de la solidaridad que tanto el rey Juan Carlos como el presidente del Gobierno acaban de pedirnos a todos nosotros.

Tres son los niveles que debemos considerar al estudiar el problema del paro:

1. Colocación de trabajadores en paro.

2. Medidas a tomar para evitar que el paro aumente por la incorporación anual de unos 200.000 jóvenes al mercado de trabajo.

3. Creación de nuevos puestos de trabajo para compensar las futuras reducciones de plantillas previstas en las necesarias reconversiones sectoriales y de empresas. teriores?

¿Cuáles son las soluciones posibles para cada uno de los niveles an-

\section{Colocación de trabajadores en paro}

Hoy el trabajo disponible es un bien escaso. Por ello siempre se ha con- 


\section{FERNANDO BIANCHI}

siderado como una solución el repartirlo entre todos los trabajadores disminuyendo las horas de trabajo.

Pero si se disminuyen las horas de trabajo sin disminuir al mismo tiempo los salarios, el coste de producción en las empresas aumenta, lo que sería muy difícilmente absorbido por muchas empresas dada su difícil situación económica actual. De otra parte, una disminución de salarios correspondiente a la disminución de las horas de trabajo, tampoco podría ser fácilmente aceptado por los trabajadores debido a que les supondría una baja inmediata de su nivel de vida.

Ante esta situación una solución se apunta como posible, en la línea de la que acaba de ser acordada en Holanda entre los sindicatos de trabajadores y las empresas. Y sería la siguiente:

Que en los actuales Convenios Colectivos que se van a negociar para 1983 los sindicatos y los empresarios acuerden los siguientes puntos:

1. Que el aumento de salarios a negociar en el Convenio no se cobre por los trabajadores que hoy están trabajando, sino que se disminuyan en el mismo porcentaje sus horas de trabajo.

2. Que la disminución anterior de horas de trabajo se cubra tomando la empresa trabajadores en paro.

3. Que los trabajadores en paro que entren a trabajar en una empresa, de acuerdo con lo anterior, cobrarán los mismos salarios que los trabajadores en activo de dicha empresa, a cargo del porcentaje de aumento salarial acordado en el convenio.

Podría aplicarse una solución menos radical y más flexible, es decir, que sólo una parte del aumento de salarios acordado en el Convenio se destine a aumentar los salarios de los trabajadores que hoy estan trabajando, y la otra parte se destine a poner en práctica la solución más arriba señalada, si bien en este caso los salarios de los trabajadores en paro que entren a trabajar en las empresas podrían ser inferiores al nuevo salario de los trabajadores hoy en activo.

Un ejemplo para clarificar la anterior propuesta. La población activa actual en España es de unos 13.000 .000 de trabajadores, de los cuales unos 2.200 .000 están en paro, pudiendo por lo tanto considerar que la actual población activa con trabajo es de unos 10.800 .000 de trabajadores.

Supongamos que en el próximo Convenio Colectivo se acuerda un aumento de salarios del 12 por 100 (cifra tomada solamente a título de ejemplo). Si se rebajan las horas de trabajo en este 12 por 100 y se cubren estas horas con trabajadores en paro, habría trabajo para 1.280 .000 trabajadores en paro ( 12 por 100 de 10.800 .000 ), que podrían cobrar con el 12 por 100 de aumento de salarios pactado, el mismo salario que actualmente cobran los 10.800.000 de trabajadores que ahora tienen trabajo.

Esta solución supondría un gran acto de solidaridad de los trabajadores 
que hoy están trabajando con sus compañeros en angustiosa situación de paro, y muchos de ellos sin cobro de ningún subsidio, ya que si bien tendrían el beneficio de una disminución del 12 por 100 de sus horas de trabajo, no tendrían aumento de salario por este año, lo que les supone una disminución futura de su actual nivel de vida. Por el contrario 1.280 .000 trabajadores en paro tendrían trabajo. Esta es la solución más radical y más utópica. Piénsese en fórmulas más flexibles como serían el renunciar a la mitad o sólo a un tercio del aumento salarial y en la misma proporción las horas de trabajo.

Para las empresas, esta solución, no supone ningún aumento ni de sus horas de trabajo ni de sus retribuciones totales por encima de lo pactado en el Convenio, y si bien el disminuir las horas de trabajo de la plantilla actual y compensarlo con un 12 por 100 (o menos según la fórmula aplicada) de aumento de plantilla puede suponer, quizás, una pequeña dificultad más psicológica que real, la empresa se vería ampliamente compensada por su solidaridad con los trabajadores en paro.

Comentada esta solución con algunos directivos sindicales, su primera impresión fue la de que "siempre tienen que ser los trabajadores los que solucionen los problemas, ¿̇es que los demás no van a hacer nada en favor de los parados?".

Bien mirada la propuesta, parece que en la solución apuntada la "clase trabajadora" no sale perjudicada ya que lo que dejan de cobrar los trabajadores que hoy tienen trabajo, lo cobran los trabajadores en paro que entran a trabajar.

Por otra parte esta solución estaría dentro del programa del Gobierno en cuanto a su interés de "que se mantuviera el poder adquisitivo del conjunto de la renta salarial" según acaba de declarar el presidente del Gobierno.

Y en cuanto a la aportación de las otras clases sociales a la solución del paro, ésta se centra, en su aportación económica para la posible creación de 200.000 puestos de trabajo anuales, según se expone a continuación.

2. Medidas a tomar para evitar que el paro aumente por la incorporación anual de unos 200.000 jóvenes al mercado de trabajo.

Para esto es preciso que se cumpla el programa del PSOE de crear 200.000 puestos de trabajo anuales en los próximos cuatro años.

Las necesidades de dinero para la creación de los anteriores puestos de trabajo deben provenir de impuestos directos que graven a las personas con más posibilidades económicas, contribuyendo de esta manera a la solidaridad general con el grave problema humano de los parados, al igual que los trabajadores que tienen hoy puesto de trabajo contribuyen al problema de los parados dejando de cobrar el aumento de salarios pactado en el Convenio. 


\section{FERNANDO BIANCHI}

3. Creación de nuevos puestos de trabajo para compensar las futuras reducciones de plantillas previstas en las necesarias reconversiones sectoriales y de empresas.

La creación de nuevos puestos de trabajo pasa necesariamente por hacer que las empresas sean eficaces, es decir competitivas en un mercado internacional.

En el Segundo Simposio Internacional de Economía Social de Mercado celebrado en Madrid (diciembre 1980) ya se planteó esta cuestión: "Necesariamente cualquier planteamiento que quiera buscar una respuesta positiva al paro, mejorando los niveles de ocupación y facilitando la reestructuración económica, pasa por la acción en la empresa. Ya se trate de una actividad en la empresa privada, o bien se trate de su realización a través de la empresa pública, estas dos instituciones empresariales constituyen el eje central de la respuesta a la ocupación y reestructuración económica." (...) "Debemos convencernos de que el paro no tendrá solución alguna si la empresa no actúa de forma eficaz. Y con ello me refiero tanto a la empresa privada como a la pública... Lo que hay que pensar fundamentalmente es que cuando una economía, como la española, cae en situaciones de letargo y no es capaz de dar los pasos suficientes para modificar sus estructuras económicas, el paro no tiene respuesta. Y aquí es donde se plantea fundamentalmente el problema del momento actual español."

Aparte de las medidas macroeconómicas que pueda tomar el Gobierno para reactivar el mercado nacional, es opinión unánime que la creación de nuevos puestos de trabajo está en función de las posibilidades de exportación de nuestras empresas, es decir, de acudir competitivamente al mercado internacional.

Un mercado internacional en crisis, con millones de parados, se caracteriza hoy: $1 .^{\circ}$ ) por una extraordinaria competencia japonesa basada en sus fábricas montadas en países subdesarrollados del suroeste asiático - Corea, Formosa, Singapur-con niveles de salarios muy inferiores a los nuestros y a los europeos, así como por la "robotización" de sus industrias establecidas en su propio país; y $2 .^{\circ}$ ) por una, también fuerte competencia, de la potente industria europea concentrada y bien mecanizada, como resultado de los muchos años de funcionamiento del Mercado Común Europeo.

La gravedad de la competencia japonesa en Europa es tal, que el próximo Consejo de Ministros de Asuntos Exteriores de los diez, tiene previsto estudiar diversas proposiciones para convencer al Japón de la necesidad de que se autolimite sus exportaciones a Europa, ya que los precios a los que está ofreciendo sus artículos son imposibles de competir por los fabricantes europeos. Philips ha anunciado que si los japoneses siguen ofreciendo sus vídeos a los precios tan increíblemente bajos como lo están haciendo, tendrá que despedir a 10.000 trabajadores ante la imposibilidad de competir con los precios japoneses.

En estas circunstancias el que nuestras empresas puedan exportar, sola- 
mente será posible a través de un gran esfuerzo solidario de los empresarios, trabajadores, sindicatos, bancos y cajas de ahorro, partidos políticos y Administración, ya que las posibilidades de exportación dependerán de que las empresas puedan alcanzar precios de venta competitivos ( $y$ por lo tanto precios de coste adecuados) con los que rigen en el mercado internacional.

Al igual de lo que ya está sucediendo en los actuales planes de reestructuración sectoriales, basados en los planes de viabilidad de las empresas pertenecientes a dichos sectores, el alcanzar precios de coste competitivos en nuestras empresas a nivel internacional, exigirá fuertes sacrificios a los accionistas y trabajadores, a los bancos y a la Administración.

El grado de los sacrificios exigidos variará en cada caso en función de la situación de cada empresa en relación con su mercado internacional.

Es lógico que solamente podrá pedirse fuertes sacrificios a los trabajadores: $\left.1^{\circ}{ }^{\circ}\right)$ si se les demuestra fehacientemente que tales sacrificios son verdaderamente necesarios para la continuidad de la vida de la empresa, y por tanto de los puestos de trabajo, y que son proporcionales a los sacrificios de las demás partes interesadas en la continuidad de la empresa; $2 .^{\circ}$ ) si a partir de ese momento, los trabajadores, toman parte a través de sus representantes en las decisiones económicas de la empresa -COGESTION PARITARIA como en Alemania-; y $3 .^{\circ}$ ) si se fija en negociación una participación en los beneficios de la empresa que les compense, en el futuro, su actual sacrificio económico.

Esta solidaridad y colaboración de todos los agentes económicos que intervienen en la marcha de la empresa, es completamente imprescindible para poder afrontar los muy difíciles problemas que han de plantearse a nivel de cada empresa, para solucionar el tema de la obtención de precios de coste competitivos a nivel internacional que permita la expansión de sus exportaciones, y como consecuencia la creación de nuevos puestos de trabajo.

Es indudable que este problema de alcanzar precios competitivos que permitan exportar, no será el mismo para todas las empresas sino que en cada empresa tendrá sus características propias; de ahí la necesidad de que se establezca la cogestión con carácter general, para que la aportación que deben prestar los trabajadores esté en relación con la situación de su propia empresa.

Sin olvidar que el derecho de los trabajadores a la cogestión, es decir a la codecisión de los trabajadores juntamente con los capitalistas en los órganos de gestión económica de las empresas, es un derecho de justicia social incuestionable. Juan Pablo II en su reciente encíclica "Laborem exercens" (septiembre 1981) señala: "Se debe ante todo, recordar un principio enseñado siempre por la Iglesia. Es el principio de la prioridad del trabajo frente al "capital". Este principio se refiere directamente al proceso mismo de producción, respecto al cual el trabajo es siempre una causa eficiente primaria, mientras el capital siendo el conjunto de los medios de producción, es sólo un instrumento o causa instrumental. Este principio es una verdad evidente, que se deduce de toda la experiencia histórica del hombre." 


\section{FERNANDO BIANCHI}

Tampoco puede olvidarse que "la situación actual se caracteriza por una debilidad de la demanda interior, con altos niveles de inflación y paro; y por una recesión económica internacional", (...) "En tales circunstancias, la mejora de la productividad se plantea como la única vía posible de superación de las graves dificultades con que hoy se encuentra la economía española." (...) "Estudios y experiencias concretas recientemente realizadas demuestran el hecho de que alejar a los trabajadores de los centros de decisión favorece el absentismo, de la misma forma que cuando se proporcionan cauces para la participación del trabajador en la toma de decisiones, mejora la productividad." (Dirección y Progreso, nov.-dic. 1980.)

Naturalmente, todo ello, apoyado por una política macroeconómica de "flotación" o cambio variable de la peseta, y por una política de negociación con la Comunidad Económica Europea, que ayuden a los esfuerzos de exportación de las empresas. 